УДК 338.1

В. С. Александрова

Университет ИТМО, Санкт-Петербург, e-mail: valeria.alexandrova5@gmail.com

В. И. Юхимец

Университет ИТМО, Санкт-Петербург, e-mail: yukhimets.99@mail.ru

А. В. Лихвойнен

Университет ИТМО, Санкт-Петербург, e-mail: likhvoynen@yandex.ru

А. В. Филиппович

Университет ИТМО, Санкт-Петербург, e-mail: andrejfilippovic8@gmail.com

Е. В. Первухина

Университет ИТМО, Санкт-Петербург, e-mail: per.ekat98@gmail.com

РЫНОК КРЕАТИВНЫХ ТЕХНОЛОГИЙ:
СОВРЕМЕННОЕ СОСТОЯНИЕ И ПЕРСПЕКТИВЫ РАЗВИТИЯ

Ключевые слова: рынок креативных технологий, креативные индустрии, искусственный интеллект, виртуальная реальность, дополненная реальность, разработка игр, разработка программных продуктов.

В статье представлено многостороннее рассмотрение рынка Creative Technologies (креативных технологий). Сектор Creative Technologies связан с интеллектуальной, творческой деятельностью человека с использованием новых, чаще всего цифровых технологий. Характер развития человека изменяется под влиянием формирования креативного сознания. Именно креативные технологии являются одним из драйверов инновационного развития стран, они несут в себе не только коммерческую составляющую, но и культурную. В ходе работы была произведена сегментация рынка креативных технологий, а также выявлены приоритетные на сегодняшний день направления данной области. Проанализирован размер рынка Creative Technologies на основе трех приоритетных областей. Также в ходе работы выявлены самые успешные IPO и сделки на рынке Creative Technologies, oпределены основные тенденции и перспективы развития данного сегмента. Рассмотрев рынок Creative Technologies, можно сделать вывод, что креативные технологии диктуют свои условия развития общества и личности в нем, планомерно изменяя определенные отношения и права. Данный сектор показывает положительную динамику на протяжении нескольких лет, что обуславливает его значимость и востребованность на данном этапе развития общества.

\title{
V.S. Alexandrova
}

University ITMO, Saint Petersburg, e-mail: valeria.alexandrova5@gmail.com

\section{I. Yukhimets}

University ITMO, Saint Petersburg, e-mail: yukhimets.99@mail.ru

\section{A. V. Likhvoynen}

University ITMO, Saint Petersburg, e-mail: likhvoynen@yandex.ru

A. V. Filippovich

University ITMO, Saint Petersburg, e-mail: andrejfilippovic8@gmail.com

\section{E. V. Pervukhina}

University ITMO, Saint Petersburg, e-mail: per.ekat98@gmail.com

\section{THE MARKET OF CREATIVE TECHNOLOGIES: CURRENT STATE AND PROSPECTS OF DEVELOPMENT}

Keywords: Creative Technologies market, creative industries, artificial intelligence, virtual reality, augmented reality, game development, software development.

The article presents a comprehensive review of the Creative Technologies market. The Creative Technologies sector is associated with intellectual, creative human activity using new, most often digital technologies. The nature of human development changes under the influence of the formation of creative consciousness. It is creative technologies that are one of the drivers of innovative development of 
countries, they carry not only a commercial component, but also a cultural one. In the course of the work, the market of creative technologies was segmented, and priority areas of this area were identified today. The size of the Creative Technologies market is analyzed based on three priority areas. In addition, the most successful IPOs and deals on the Creative Technologies market are identified, and the main trends and prospects for the development of this segment are identified. Looking at the Creative Technologies market, we can conclude that creative technologies dictate their own conditions for the development of society and the individual in it, systematically changing certain relationships and rights. This sector has been showing positive dynamics for several years, which determines its importance and relevance at this stage of society's development.

Сектор Creative Technologies связан с интеллектуальной, творческой деятельностью человека с использованием новых (чаще всего цифровых) технологий.

Характер развития человека изменяется под влиянием формирования креативного сознания. На сегодняшний день прибыльным является максимизация использования интеллектуального капитала, а не реновация старых вещей, которые занимали важное место на прошлых этапах развития человечества [1].

Что касается денежного вопроса, то на первое место выходит наличие уникальных технологий, которые определяют конкурентное преимущество. Деньги теряют свою первостепенность, они становятся не главным источником рыночной силы, а всего лишь следствием. Креативные технологии диктуют свои условия развития общества и личности в нем, планомерно изменяя определенные отношения и права.

Мировой сектор креативных технологий развивается даже во время различных кризисов. Рассмотрим ситуацию с распространением COVID-19, на фоне карантинных мероприятий акции различных компаний падали, а вот стриминговые сервисы ощутили подъем. Продажи видеоигр увеличились почти на $63 \%$ в 50 странах мира [2]. Некоторые эксперты полагают, что в недалеком будущем сырьевую модель заменит креативная модель.

Таким образом, сектор Creative Technologies показывает достаточно хорошие темпы развития, затрагивая различные сферы деятельности человека. Рассмотрим, какие основные направления креативных технологий преобладают на данном этапе развития человечества, каковы их основные характеристики и перспективы.

Целью работы является определение современного состояния рынка креативных технологий, а также тенденций и перспектив развития данного сектора.
Для решения поставленной цели в работе рассматриваются следующие задачи:

1) определение размера рынка Creative Technologies и его значимости;

2) сегментация рынка Creative Technologies;

3) выявление приоритетных направлений рынка Creative Technologies;

4) выявление самых успешных IPO на рынке Creative Technologies;

5) выявление наиболее известных и свежих сделок на рынке Creative Technologies;

6) определение основных тенденций развития рынка Creative Technologies;

7) определение основных неудовлетворенных рыночных потребностей и перспектив развития.

Материал и методы исследования: основными методами в работе выступает анализ информации из печатных изданий и интернет-источников, синтез полученной информации, а также социологический опрос.

Свое исследование начнем с определения значения сектора Creative Technologies.

Сектор Creative Technologies представляет собой сектор экономики, в основе которого лежит интеллектуальная деятельность. Капитализация креативных индустрий на сегодняшний день составляет около \$2,3 трлн. Если рассмотреть США, то там около 30 млн рабочих мест создано именно сферой креативных технологий [3].

Креативные технологии становятся драйверами развития экономики в развитых и развивающихся странах. Темпы развития данного сектора превышают темпы развития традиционной промышленности или же других отраслей. Данное обстоятельство можно связать в первую очередь с высокой добавленной стоимостью продукции креативных технологий. Также не стоит забывать о специфики данного сектора, так как он привлекает большое количество молодежи. 
Следует сказать, что в мире нет единой сегментации рынка креативных технологий. Данная проблема берет свое начало с того, что в одних странах частью креативной экономики не считают, например, туризм, научно-техническую деятельность, в других медицину и национальную кухню. Границы сектора постоянно меняются, как и меняется сама жизнь. Таким образом, можно сказать, что нет стандартной основы рынка креативных технологий.

В Великобритании глубоко занимаются вопросом определения значимости и границ рынка креативных индустрий, используя при этом разнообразные статистические коды. Тем самым, можно рассматривать сегментацию рынка креативных технологий, разработанную Государственным Департаментом Великобритании по цифровым технологиям, культуре, СМИ и спорту (DCMS). Она выглядит следующим образом (рисунок 1):

На сегодняшний день можно выделить три приоритетных направления развития рынка креативных технологий, а именно, искусственный интеллект, дополнительная и виртуальная реальность, игры и программные продукты. На данные области приходится основная доля рынка креативных технологий, а также в них концентрируется основная сумма инвестиций. Рассмотрим каждое направление подробнее.

Искусственный интеллект представляет собой интеллектуальную систему, которая способна выполнять различные творческие функции, обычно считающиеся прерогативой человека.

Рынок искусственного интеллекта стремительно набирает обороты, его можно увидеть в различных областях, это может быть потребительский рынок, государственный сектор, военный сектор и т. д. Согласно мнению исследовательского агентства Tractica, рынок искусственного интеллекта в 2020-м году вступил в новую эпоху, которая гласит, что искусственный интеллект необходим для компаний, которые стремятся конкурировать на рынке.

По данным опроса, который был проведен TAdviser, более $85 \%$ российских организаций используют или пробуют использовать в своей деятельности различные технологии, связанные с искусственным интеллектом [4].

Объем российского рынка искусственного интеллекта в 2020 году составил около 28 млрд руб. Инвестиции в исследование и разработку данной области за 2007 2017 годы составили 23 млрд руб. Основываясь на исследованиях ReportCrux Market Research, можно сделать вывод, что глобальный спрос на искусственный интеллект в 2019 году оценивается в \$2,64 млрд. Прогноз говорит о увеличении выручки в среднем на $25 \%$ в год за период с 2020 года по 2027 год, тем самым к конку 2027 года выручка составит $\$ 15,72$ млрд [4].

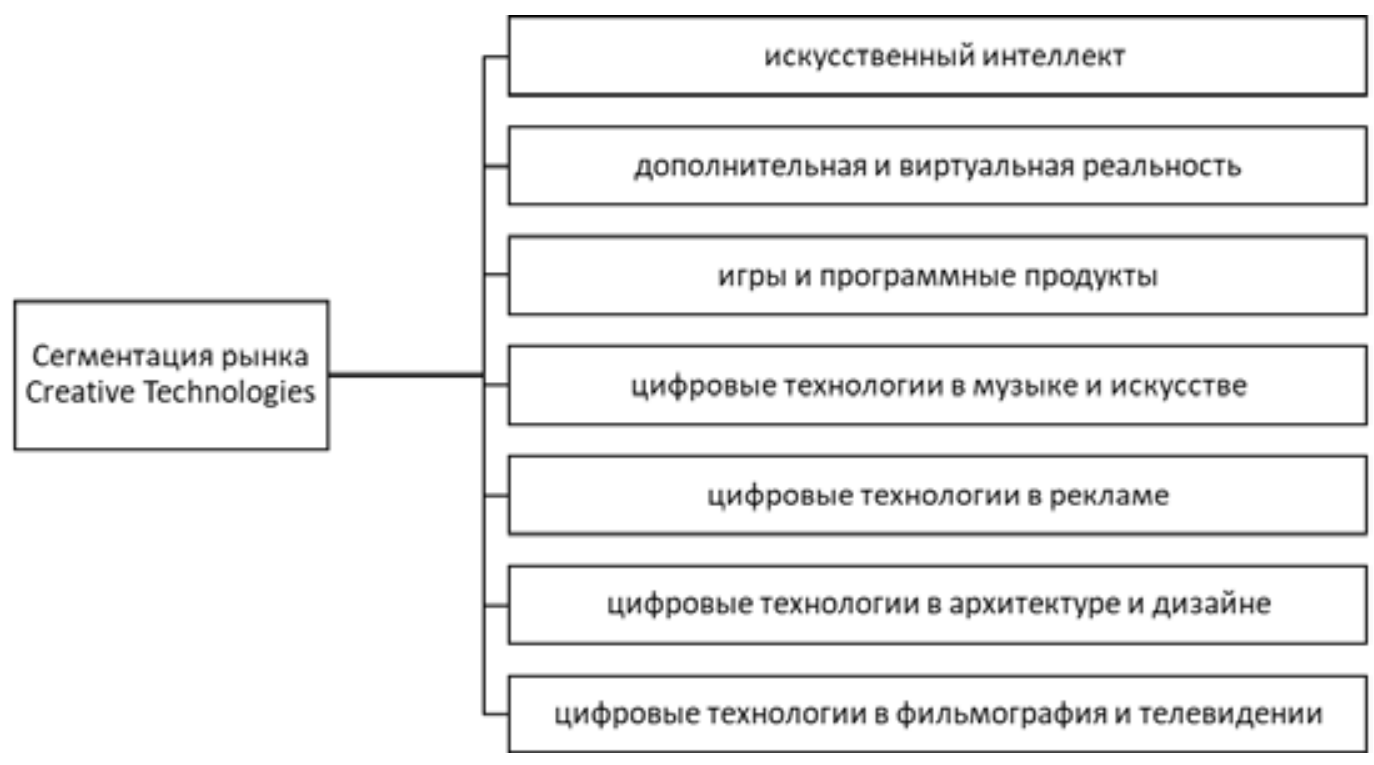

Puc. 1. Сегментация рынка Creative Technologies 
Примерами работы искусственного интеллекта могут служить различные приложения, например, Spotify, Netflix, YouTube, Instagram, Snapchat и многие другие.

Далее рассмотрим сферу игр и программных продуктов, которая также показывает положительную динамику. Число геймеров постоянно растет, в 2019 году их насчитывалось около 2,5 млрд человек [5]. Сам же гейминг становится высокооплачиваемой профессией. Вокруг игровой индустрии формируется своего рода экосистема, которая включает не только разработчиков и издателей игр, но и профильные СМИ, различные методы продвижения и инфраструктуруа (интернет-кафе, локации для турниров по видеоиграм).

Совместными усилиями ряд аналитических компаний Newzoo, UKIE, Sensor Tower, IHS Markit, ICO Partners и Fancensus составили отчет по рынку игр на 2019 год. Ключевой информацией является то, что общий объем рынка игр в 2019 году составил порядка \$148,8 млрд, около 46\% рынка приходится на игры для смартфонов и планшетов, $30 \%-$ на консольные игры, 24\% - на ПК-игры [6].

Руководствуясь данными аналитической компании SuperData, можно говорить о том, что за первую половину 2020 года россияне потратили около \$1,14 млрд на игры. Данная цифра превышает сумму, которую россияне потратили за первое полугодие 2018 года, на $21 \%$. Основная доля, а именно, $43,5 \%$ данных денежных средств приходится на мобильные приложения [7].

Аналитическая компания App Annie опубликовала данные, согласно которым в 2019 году россияне установили около 5125 млн приложений, в день на данные приложения в среднем уходило 3 часа 40 минут. Больше всего денег тратится в приложении Вконтакте, Boom, Ivi. По скачиванию на первом месте расположился WhatsApp, на втором - «Сбербанк Онлайн» [8].

Перейдем к продуктам виртуальной и дополненной реальности (VR/AR).

Виртуальная реальность - технологии, которые создают мир, передавая его человеку через органы чувств: зрение, слух, обоняние, осязание. А дополненная реальность представляет собой технологии, которые лишь дополняют реальный мир, добавляют некоторые сенсорные данные. Эти технологии могут и привносить что-то новое в реальный мир, так и убирать из него какие-либо объекты [9].
Рынок виртуальной и дополненной реальности постоянно развивается, так как данные технологии применяются в игровой и банковской сфере, медицине, образовании и т. д.

В 2019 году в сферу VR/AR было вложено около \$4,1 млрд. Большинство проектов было предложено и проинвестировано в США и Китае. Что касается России, то здесь также ведется поддержка проектов в области виртуальной и дополненной реальности, например, в 2019 году финансовая помощь была оказана 23 проектам, а общая сумма вложенных средств составила 653 млн руб. [10].

В качестве примеров копаний сектора Creative Technologies рассмотрим самые успешные IPO данного сектора за последних несколько лет.

Первым хотелось бы отметить IPO Pinterest, которое началось 18 апреля 2019 года. Pinterest - платформа, где пользователи размещают разнообразные изображения, составляют их них тематические коллекции, а также делятся этими коллекциями с публикой. Стартовая стоимость акций на момент начала торгов составляла $\$ 23,75$. На IPO компания заработала порядка \$1,4 млрд. Можно отметить несколько причин ажиотажа: благоприятный контент, улучшение финансовых показателей (в 2018 году компания снизила свои убытки на $62 \%$ по сравнению с 2016 годом), а также доверие инвесторов. В настоящий момент рыночная капитализация Pinterest составляет около \$15,8 млрд., а стоимость акции находится в диапазоне от \$27 до \$29.

Также хотелось бы рассмотреть IPO Spotify, которое началось 30 апреля 2018 года. Spotify - шведский музыкальный сервис, который позволяет бесплатно прослушивать аудиокниги, музыку и подкасты, не скачивая их на свой гаджет. Стартовая стоимость акций на момент начала торгов составляла $\$ 165,90$. На IPO компания заработала порядка \$9,2 млрд. Причины ажиотажа: позиционирование, новый подход к бизнесу и амбициозные прогнозы компании. В настоящий момент рыночная капитализация Spotify составляет \$24,9 млрд., а стоимость акции находится в диапазоне от $\$ 130$ до $\$ 140$.

Н рынке креативных технологий постоянно совершаются разнообразные сделки, связанные с приобретением каких-либо компаний, технологий, прав и т.д. В таких сделках аккумулируются достаточно боль- 
шие суммы денежных средств, что обуславливает развитие данного сектора экономика, а также его важную роль на современном этапе развития. Рассмотрим три наиболее интересные сделки на рынке Creative Technologies:

1) одна из известных социальных сетей, а именно, Facebook совершила сделку по покупке компании Oculus VR, которая занимается производством очков для виртуальной реальности. Сделка оценивается в \$2 млрд. Около 20\% суммы сделки Oculus VR получит в виде наличности, оставшиеся $80 \%$ будут переданы посредством акций Facebook. Марк Цукерберг заявляет, что приобретенная компания является платформой будущего.

2) компания Microsoft приобрела холдинг ZeniMax Media, который является материнской компанией Bethesda Softworks, издателя таких популярных видеоигр, как Fallout, Doom и Skyrim. Сумма сделки оценивается в \$7,57 млрд.

3) корпорация Apple также не осталась в стороне. Она приобрела компанию Vrvana, которая занимается разработкой гарнитур дополненной реальности. Сумма сделки оценивается в \$30 млн. Тем самым Apple дал понять, что планирует выпуск собственной гарнитуры дополненной реальности.

Что касается основных тенденций развития рынка Creative Technologies, то здесь можно выделить несколько основных моментов:

1) наступление эры «интернет поведения», которая означает, что большое количество различных устройств человек будет носить на себе или даже внедрять в организм;

2) масштабное развитие креативных технологий в образовательной сфере;

3) увеличение доли квалифицированных кадров для данного сегмента.
В ходе работы был проведен социологический опрос, в котором экспертам был задан ряд вопросов:

1) знаете ли Вы, что из себя представляет сектор Creative Technologies (сектор креативных технологий);

2) пользуйтесь ли Вы продукцией сектоpa Creative Technologies;

3) где чаще всего Вы видите продукцию сектора Creative Technologies;

4) расположите направления рынка Creative Technologies в порядке убывания значимости, где 1 - самый значимый, 7 - самый незначимый;

5) какие неудовлетворенные потребности существуют в данном секторе на Ваш взгляд.

Проанализировав ответы экспертов, были получены следующие результаты:

1) $34 \%$ опрошенных знают о секторе Creative Technologies, 47\% могут описать сектор общими фразами, 19\% - не знают о существовании такого направления;

2) так как многие просто не сталкивались с понятием «сектор Creative Technologies», после объяснения выяснилось, что 100\% опрошенных пользуются продукцией данной сферы (игры, приложения, искусственный интеллект в различных областях деятельности и другое);

3) продукцию сектора чаще всего наблюдают в игровой сфере;

4) первые три направления ранжированного списка соответствуют разобранным выше, на 4 месте - цифровые технологии в музыке, искусстве, на 5 месте - цифровые технологии в фильмография и телевидении, на 6 месте - цифровые технологии в архитектуре и дизайне, на 7 месте - цифровые технологии в рекламе.

5) к основным неудовлетворенным рыночным потребностям эксперты отнесли следующее (рис. 2).

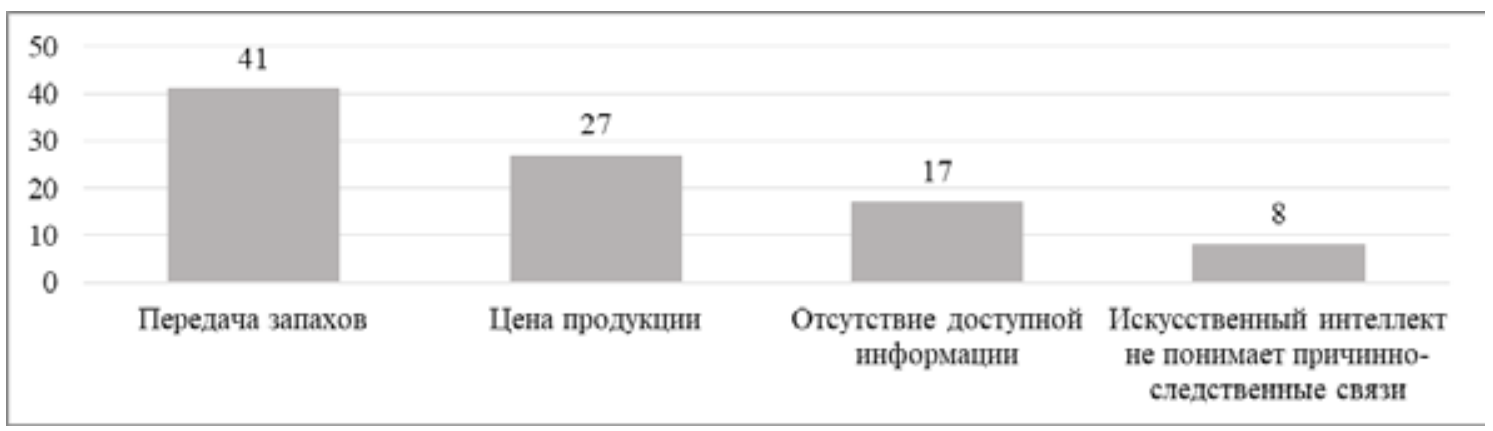

Рис. 2. Основные неудовлетворенные рыночные потребности, в \% к общему количеству ответов 
Таким образом, в качестве перспектив развития сектора Creative Technologies можно рассмотреть возможность передачи запахов с помощью различных гаджетов, снижение цены продукции креативной индустрии, размещение актуальной и доступной для всех информации о состоянии сектора креативных технологий и новой продукции.

Руководствуясь вышеперечисленным, можно сделать вывод, что сектор Creative Technologies в настоящее время развивается достаточно быстро. Креативные технологии становятся драйверами развития стран [11]. Многие компании видят потенциал развития в данном секторе, в результате чего осуществляется процесс разработки или покупки разнообразных интересных и инновационных технологий, позволяющих привлечь большее количество клиентов, а также преимущества в плане реакции на изменение ситуации на рынке. Большое количество стартапов возникает и развивается в данном секторе, так как он привлекает много активной молодежи, желающей изменений.

Даже во время пандемии COVID-19 сектор креативных технологий показал доста- точно хорошую динамику, по сравнению с другими сферами, в которых активность во многом снизилась или же полностью прекратилась. Много сделок заключалось между разработчиками игр и приложений, различными технологическими компаниями.

Следует отметить увеличение популярности цифрового пространства, которое открывает большие возможности для развития креативных технологий. Вместе с тем на сегодняшний день наблюдается тенденция к максимальному использованию интеллектуального капитала, так как именно он приносит достаточно большую добавленную стоимость.

Креативные технологии можно использовать повсеместно, это может быть медицина, промышленность, градостроительство, транспорт, образование, развлечения и многое другое. Во многих странах существуют разнообразные методы поддержки и стимулирования данного сектора.

Таким образом, сектор Creative Technologies - драйвер развития, технологии которого играют огромную роль в становлении современного общества.

\section{Библиографический список}

1. Филиппова Н.Н. Формирование рынка креативных технологий // Креативная экономика. 2007. Т. 1. № 5. С. 74-82.

2. Творчество как товар. Как развивается креативная экономика в России? [Электронный ресурс]. Режим доступа: https://polit.ru/article/2020/08/24/creative (дата обращения: 11.01.2021).

3. Что такое креативные индустрии? [Электронный ресурс]. Режим доступа: https://rends.rbc.ru/trends/ innovation/5dd54dbf9a79471180f57ce7 (дата обращения: 11.01.2021).

4. Искусственный интеллект (мировой рынок) [Электронный ресурс]. Режим доступа: https://www. tadviser.ru/index.php/Статья:Искусственный_интеллект_(мировой_рынок) (дата обращения: 11.01.2021).

5. Компьютерные и видеоигры (мировой рынок) [Электронный ресурс]. Режим доступа: https://www. tadviser.ru/index.php/Статья:Компьютерные_и_видеоигры_(мировой_рынок) (дата обращения: 11.01.2021).

6. GamesIndustry.biz presents... The Year In Numbers 2019 [Электронный ресурс]. - Режим доступа: https:// www.gamesindustry.biz/articles/2019-12-17-gamesindustry-biz-presents-the-year-in-numbers-2019?ref=vc.ru (дата обращения: 11.01.2021).

7. Russia to Become the Third Biggest European Market for Video Games 2019 [Электронный ресурс]. Режим доступа: https:/www.superdataresearch.com/blog/russia-to-become-the-third-biggest-european-marketfor-video-games (дата обращения: 11.01.2021).

8. The State of Mobile 2021 [Электронный ресурc]. Режим доступа: https://www.appannie.com/ru/go/ state-of-mobile-2021/ (дата обращения: 11.01.2021).

9. Виртуальная реальность vs Дополненная реальность [Электронный ресурс]. Режим доступа: https:// habr.com/ru/company/ua-hosting/blog/393835/ (дата обращения: 11.01.2021).

10. Рынок устройств виртуальной и дополненной реальности [Электронный ресурс]. Режим доступа: https://www.tadviser.ru/index.php/Статья:Рынок_устройств_виртуальной_и_дополненной_реальности (дата обращения: 11.01.2021).

11. Новикова С.К. Креативная экономика как драйвер роста: мировой и российский опыт // Новые технологии. 2019. № 2. С. 175-184. 